\title{
Utilização de um sistema de gerenciamento de benefícios farmacêuticos (PBM) para a caracterização do perfil de prescrição e aquisição de antibióticos
}

\author{
Ana Paula Cunha S. Lima ${ }^{1}$, Neucenir Roberti Gallani ${ }^{2}$, Maria Inês de Toledo ${ }^{3}$, Luciane C. Lopes ${ }^{4 *}$ \\ ${ }^{1}$ AFARCAMP, ${ }^{2}$ SYMCO Institute, ${ }^{3}$ Centro de Referência e Informação sobre Antibióticos (CRIA), Universidade de \\ Sorocaba, ${ }^{4}$ Curso de Farmácia, Universidade de Sorocaba
}

*Correspondência:

L. C. Lopes

Universidade de Sorocaba

Av. Eugênio Salerno, 100

18035-430 - Sorocaba - SP, Brasil

E-mail: luslopes@terra.com.br
No Brasil o PBM (Pharmacy Benefits Management) é de utilização relativamente nova, podendo-se classificá-lo como um sistema de gerenciamento de saúde que administra beneficios na compra e venda de medicamentos. Considerando que o surgimento de bactérias resistentes está relacionado à prescrição inapropriada de antibióticos ou ao uso de antibióticos de baixa atividade, este estudo avaliou se o sistema PBM pode fornecer informações úteis sobre os perfis de prescrição e aquisição de antibióticos de efeitos sistêmicos, a partir da base de dados de uma empresa de PBM brasileira, referente a um grupo formado por 6525 metalúrgicos de uma empresa da região de Campinas, SP, e seus dependentes, cobrindo o periodo de janeiro a abril de 2005. Observou-se que 7,7\% de todos os medicamentos adquiridos eram antibióticos sistêmicos, numa média 2,4 antibióticos e ao custo de $R \$ 51,80$ por receita. A amoxicilina foi o fármaco mais prescrito e em 92,7\% dos casos o usuário adquiriu o medicamento até um dia após a consulta médica. A partir das listas das especialidades farmacêuticas adquiridas (por unidade de venda), dos laboratórios fabricantes, dos antibióticos que compunham cada produto, das datas de emissão das receitas e da dispensação, foi possivel concluir que o sistema permite extrair informações relevantes sobre o tema enfocado.
Unitermos

- Gerenciamento de benefícios farmacêuticos

- Antibióticos/prescrição

- Medicamentos/prescrição

- Medicamentos/aquisição

\section{INTRODUÇÃO}

No Brasil o conceito de PBM (Pharmacy Benefits Management) é relativamente novo, tendo adquirido sua atual configuração no final da década de 1990. Atualmente é conhecido também como Programa de Benefícios em Me- dicamentos e Gerenciamento (ou Administração) de Benefícios Farmacêuticos.

O sistema PBM surgiu na década de 1970, quando os sindicatos norte-americanos pressionaram empregadores para a inclusão dos benefícios em medicamentos entre os direitos dos trabalhadores. O crescimento das empresas de 
managed care (gestoras de custos na área de saúde, principalmente aqueles relacionados aos serviços de segurosaúde americanos) e a concomitante expansão das empresas de PBM tiveram grande impacto na estrutura de consumo de medicamentos nos EUA. No final dos anos 1980 e início da década seguinte, a parcela da demanda de medicamentos prescritos com origem em PBMs passou de $20 \%$ para pouco mais de $50 \%$ (Mortiner, 1997).

Pode-se classificar o PBM como um sistema de gerenciamento de saúde que, envolvendo uma cadeia de informações, administra benefícios na compra e venda de medicamentos, otimizando custos, agregando valores, estreitando relacionamentos comerciais pela obtenção de vantagens operacionais e suprindo os interesses dos principais agentes envolvidos nos produtos ou serviços de saúde, a saber: os empregadores (empresas contratantes do sistema), os médicos, o varejo farmacêutico e a indústria farmacêutica (Thomas et al., 1996).

De fato, para alguns grupos terapêuticos, como por exemplo antibióticos, pode revelar-se de grande utilidade o monitoramento das informações sobre aquisição e consumo, visto que, após a introdução dessa classe farmacológica na prática clínica, há mais de 50 anos, a expansão de seu uso em infecções raramente graves tem levado ao desenvolvimento de bactérias resistentes, evento que em algumas áreas tem alcançado níveis alarmantes, a ponto de a Organização Mundial de Saúde (OMS) rotular a situação como crise global (Smith, Coast, 2002). Ainda que a tecnologia farmacêutica venha combatendo esse problema com o desenvolvimento de novos agentes, cada vez mais potentes, os principais fatores que contribuem para o surgimento de cepas resistentes são a prescrição inapropriada de antibióticos para infecções virais e o uso de antibióticos com baixa atividade (Jacobs, Weinberg, 2001) ou sem o conhecimento do microrganismo infectante.

Considerando que o banco de dados das companhias de PBM é compilado a partir das informações coletadas no momento da aquisição de medicamentos, o objetivo deste estudo é verificar se o sistema PBM pode ser utilizado como uma ferramenta para o fornecimento de informações sobre antibióticos de efeito sistêmico por meio da caracterização dos perfis de prescrição e aquisição desses fármacos, considerando-se o tipo, a quantidade de unidades de venda (caixas) adquiridas, os laboratórios envolvidos e os valores financeiros relacionados às aquisições, tendo-se em vista a emergente necessidade de controle dessa classe terapêutica.

\section{MATERIAL E MÉTODOS}

Os dados do estudo provieram da base de dados de uma empresa de PBM brasileira, sendo referentes a um grupo de consumo formado por 6525 metalúrgicos funcionários de uma empresa da região de Campinas, SP, e pelos dependentes desses funcionários. Foi considerada a totalidade das aquisições de antibióticos de ação sistêmica durante o período de janeiro a abril de 2005.

Para compreender os dados utilizados nesta pesquisa, é preciso conhecer a empresa de PBM sob o ponto de vista operacional, incluindo o banco de dados e sua origem.

Os usuários e seus dependentes recebem um cartão de crédito individual, exclusivo para utilização em farmácias e drogarias, com limite mensal de $\mathrm{R} \$ 1.000,00$. Um subsídio de $70 \%$ do valor dos medicamentos adquiridos é oferecido aos funcionários do setor produtivo e seus dependentes, desde que tais aquisições estejam devidamente apoiadas por prescrição, já que a empresa também oferece convênio médico com uma operadora de plano de saúde, além de possuir ambulatório em suas dependências. Um subsídio de $40 \%$ é oferecido aos funcionários de setores administrativos e seus dependentes.

O processo se inicia quando o usuário, munido da prescrição, realiza a aquisição em estabelecimento credenciado e, no momento do pagamento, apresenta o cartão PBM. A partir das informações armazenadas na tarja magnética, um autorizador on-line capta a elegibilidade do usuário dentro do programa, faz a interação desses dados com os itens da receita e verifica: (1) a validade do cartão do usuário, (2) o saldo disponível para debitar instantaneamente a compra, (3) o número de inscrição no CRM do prescritor e a data de emissão da receita e (4) os medicamentos adquiridos.

O sistema também está apto a fazer o cruzamento de dados do histórico de compras e verificar se há interação entre os medicamentos adquiridos nos últimos 30 dias. Em caso positivo, o farmacêutico do estabelecimento deve analisar e avaliar a dispensação. Ao final do processo é impressa uma nota de despesas e coletada a assinatura do usuário.

O banco de dados armazena as informações sobre (1) quem adquiriu o medicamento, (2) a empresa contratante do benefício, (3) o estabelecimento, data, hora e cidade em que foi realizada a compra, (4) o valor da compra, (5) a descrição do produto adquirido, (6) o laboratório fabricante, (7) os princípios ativos e (8) a classe terapêutica correspondente, segundo classificação apresentada no P.R. Vademécum (2004).

\section{Coleta e análise dos dados}

Os dados foram obtidos a partir de relatórios acessados por senha de uso restrito ao médico do trabalho ou demais profissionais, que compartilham de sigilo garantido 
por seus respectivos códigos de ética. Mesmo assim, neste estudo não foram identificados prescritores e pacientes.

Foram coletadas as listas das especialidades farmacêuticas prescritas e adquiridas que continham antibióticos, juntamente com os laboratórios fabricantes, as quantidades adquiridas por compra, os fármacos que compunham cada produto, as datas de emissão das receitas médicas e as datas de dispensação dos medicamentos. Também foram identificados, a partir da lista de medicamentos de referência divulgada pela ANVISA em seu site de acesso oficial, quais desses produtos eram medicamentos de referência e quais eram similares, visto que medicamentos genéricos são automaticamente identificados pelo sistema.

Os dados foram tabulados utilizando o programa Microsoft Excel 2000 e apresentados na forma de gráficos e tabelas.

\section{RESULTADOS}

De janeiro a abril de 2005, foram registradas as aquisições de 16010 especialidades farmacêuticas, abrangendo as várias classes farmacológicas, em 139 farmácias e drogarias da região de Campinas, totalizando $\mathrm{R} \$ 341$ 192,07. As especialidades farmacêuticas adquiridas estavam contidas em 6586 prescrições médicas, numa média de 2,4 medicamentos e ao custo médio de $\mathrm{R} \$ 51,80$, por prescrição. Foram adquiridas 1237 especialidades farmacêuticas contendo antibióticos de efeito sistêmico, correspondendo a 7,7\% do total dos medicamentos adquiridos pelo grupo de consumo, a $12,5 \%$ (825) das prescrições médicas do período e a $10,3 \%$ $(\mathrm{R} \$ 35$ 142,78) do valor total.

As especialidades farmacêuticas contendo antibióticos adquiridas corresponderam a 31 fármacos distintos, sendo que cinco delas apresentavam-se em associações. Dos 26 medicamentos com monofármacos, 14 pertenciam à Relação Nacional de Medicamentos Essenciais (RENAME) (Brasil, 2006), bem como quatro das associações, o que significa que $66,2 \%$ (819) de todas as unidades de venda com ação antibiótica adquiridas são consideradas pelo Ministério da Saúde como medicamentos essenciais (Tabela I).

As 1237 unidades adquiridas no período de estudo estavam mencionadas em 825 prescrições (em média 1,5 unidade por prescrição), uma vez que em vários casos, para se cumprir a posologia prescrita, é necessário adquirir mais de uma apresentação comercial do antibiótico. De todas as apresentações farmacêuticas prescritas, as mais freqüentes foram, respectivamente, as que continham amoxicilina, azitromicina e cefalexina (Tabela I).

Observou-se que betalactâmicos, macrolídeos e quinolonas perfizeram, respectivamente, $58,7 \%, 22,1 \% \mathrm{e}$
$10,7 \%$ das prescrições, ou seja, esses três grupos de antibióticos atenderam a mais de $90 \%$ das prescrições médicas (Figura 1).

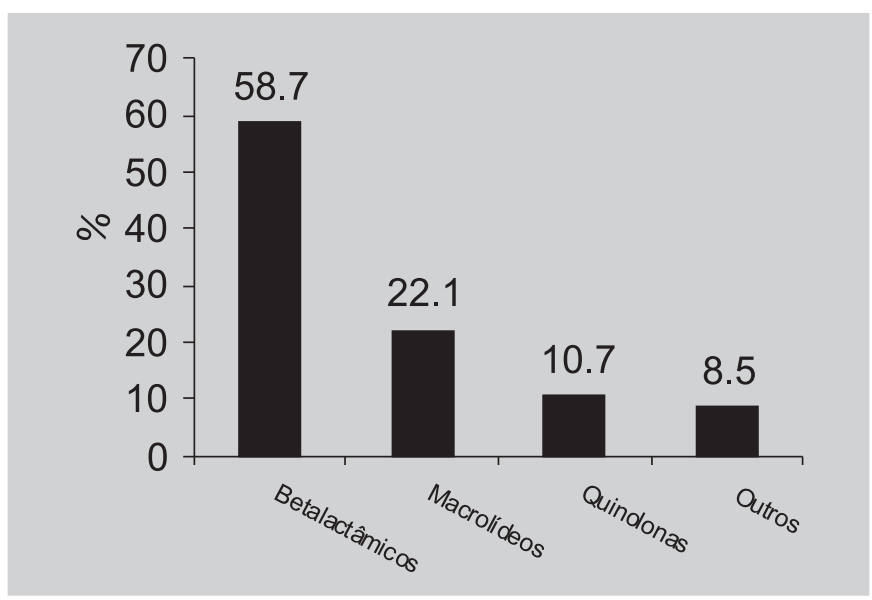

FIGURA 1 - Classes terapêuticas de antibióticos em prescrições de janeiro a abril de 2005, em sistema PBM, na região de Campinas, SP

O perfil de uso dos antibióticos mostra que $88,0 \%$ dos usuários, em quatro meses, adquiriram um medicamento com ação antibacteriana, 10,5\% adquiriram dois antibióticos diferentes e 1,5\% adquiriram três antibióticos diferentes.

Embora um grande grupo de usuários tenha adquirido um tipo de antibiótico, 93,5\% deles fizeram uma única aquisição do fármaco, 5,8\% adquiriram o mesmo tipo de antibiótico duas vezes no período de quatro meses e os demais retornaram ao estabelecimento para três ou mais aquisições, utilizando receitas diferentes em cada aquisição.

Do total de prescrições informadas pelo sistema, 13 continham pelo menos dois antibióticos diferentes em apresentações distintas. A Tabela II mostra os antibióticos encontrados numa mesma prescrição.

Verificando-se a relação dos medicamentos adquiridos (similares, genéricos ou de referência), observa-se que os genéricos foram os preferidos (Tabela III).

Quanto à participação dos laboratórios nas aquisições de especialidades farmacêuticas, observou-se que dois laboratórios forneceram $31,1 \%$ do total de unidades adquiridas (385 unidades de venda), sendo que estes produzem exclusivamente medicamentos genéricos e similares.

Foi observado também que dentre os 1237 antibióticos sistêmicos adquiridos, apenas 236 pertenciam à lista de medicamentos com desconto oferecido pelo PBM, representando um total de $19 \%$ das compras. Ressalte-se que $39 \%$ das especialidades possuíam apresentações equivalentes na lista, ou seja, 718 produtos ( $58 \%$ do total de produtos) poderiam ter sido adquiridos com descontos negociados diretamente com as indústrias farmacêuticas, uma vez 
TABELA I - Antibióticos adquiridos em unidades de venda e prescrições, em sistema PBM, de janeiro a abril de 2005, na região de Campinas, $\mathrm{SP}$

\begin{tabular}{|c|c|c|c|c|c|}
\hline \multirow{2}{*}{ Fármaco } & \multicolumn{2}{|c|}{ Prescrito } & \multicolumn{2}{|c|}{ Adquirido } & \multirow{2}{*}{$\begin{array}{c}\text { Média/ } \\
\text { Prescrição }\end{array}$} \\
\hline & $\mathrm{N}$ & $\%$ & $\mathrm{~N}$ & $\%$ & \\
\hline Amoxicilina* & 256 & 31,0 & 292 & 23,6 & 1,1 \\
\hline Azitromicina & 143 & 17,3 & 185 & 15,0 & 1,3 \\
\hline Cefalexina* & 102 & 12,4 & 282 & 22,8 & 2,8 \\
\hline Cefadroxila & 45 & 5,5 & 62 & 5,0 & 1,4 \\
\hline Norfloxacino & 44 & 5,3 & 53 & 4,3 & 1,2 \\
\hline Ciprofloxacino* & 30 & 3,6 & 37 & 3,0 & 1,2 \\
\hline Amoxicilina + Clavulanato Potássio* & 29 & 3,5 & 47 & 3,8 & 1,6 \\
\hline Cefaclor & 29 & 3,5 & 40 & 3,2 & 1,4 \\
\hline Sulfametoxazol + Trimetoprima* & 21 & 2,5 & 35 & 2,8 & 1,7 \\
\hline Claritromicina* & 21 & 2,5 & 27 & 2,2 & 1,3 \\
\hline Levofloxacino & 15 & 1,8 & 22 & 1,8 & 1,5 \\
\hline Nitrofurantoína* & 10 & 1,2 & 19 & 1,5 & 1,9 \\
\hline Cloranfenicol* & 10 & 1,2 & 10 & 0,8 & 1,0 \\
\hline Gatifloxacina & 9 & 1,1 & 9 & 0,7 & 1,0 \\
\hline Benzilpenicilina Benzatina* & 8 & 1,0 & 14 & 1,3 & 1,8 \\
\hline Sultamicilina & 7 & 0,8 & 8 & 0,6 & 1,1 \\
\hline Ceftriaxona* & 5 & 0,6 & 17 & 1,4 & 3,4 \\
\hline Ampicilina* & 5 & 0,6 & 8 & 0,6 & 1,6 \\
\hline Eritromicina* & 5 & 0,6 & 6 & 0,5 & 1,2 \\
\hline Amoxicilina + Claritromicina + Assoc. & 5 & 0,6 & 5 & 0,4 & 1,0 \\
\hline Lincomicina & 3 & 0,4 & 13 & 1,1 & 4,3 \\
\hline Limeciclina & 3 & 0,4 & 6 & 0,5 & 2,0 \\
\hline Roxitromicina & 3 & 0,4 & 6 & 0,5 & 2,0 \\
\hline Telitromicina & 3 & 0,4 & 4 & 0,3 & 1,0 \\
\hline Cefuroxima & 3 & 0,4 & 5 & 0,4 & 1,7 \\
\hline Doxiciclina* & 3 & 0,4 & 3 & 0,2 & 1,0 \\
\hline Tetraciclina & 2 & 0,2 & 8 & 0,6 & 4,0 \\
\hline Fenoximetilpenicilina Potássica* & 2 & 0,2 & 3 & 0,2 & 1,5 \\
\hline Benzilpenicilina Potássica + Procaína* & 2 & 0,2 & 2 & 0,2 & 1,0 \\
\hline Cefazolina* & 1 & 0,1 & 8 & 0,6 & 8,0 \\
\hline $\begin{array}{l}\text { Neomicina + Associações } \\
\text { (Bismu Jet solução, usada para aftas) * }\end{array}$ & 1 & 0,1 & 1 & 0,1 & 1,0 \\
\hline Total & 825 & 100 & 1.237 & 100 & 1,5 \\
\hline
\end{tabular}

*Antibióticos que constam da RENAME (Brasil, 2006)

que, para aumentar a demanda por seus produtos, estas, em parceria com a empresa de PBM, criam listas específicas com preços de fábrica diferenciados, repassados pelas distribuidoras apenas às farmácias credenciadas, na reposição das unidades de venda comercializadas através do sistema. Assim sendo, a obtenção do desconto independeria, nesses casos, de negociação no ato da compra do medicamento, sendo pré-definida automaticamente pelo sistema.

As formas farmacêuticas sólidas representaram
$73,1 \%$ de todas as aquisições. Adistribuição percentual dos antibióticos quanto à via e forma de administração é descrita na Tabela IV.

Observou-se também que $92,7 \%$ das prescrições médicas foram adquiridas até um dia após a consulta médica, sendo que $85,5 \%$ dos usuários adquiriram antibióticos no mesmo dia em que realizaram a consulta, o que dá margem a considerações acerca da facilidade na aquisição dos medicamentos prescritos. 
TABELA II - Antibióticos em prescrições contendo mais de um antibiótico sistêmico, em sistema PBM, de janeiro a abril de 2005, na região de Campinas, SP

\begin{tabular}{lc}
\hline Antibióticos prescritos & Prescrições \\
\hline Amoxicilina + Claritromicina & 4 \\
Benzilpenicilina Benzatina + Benzilpenicilina Potássica (associação com procaína) & 1 \\
Cefadroxila + Cloranfenicol & 1 \\
Levofloxacino + Nitrofurantoína & 1 \\
Azitromicina + Doxiciclina & 1 \\
Ciprofloxacino + Amoxicilina (associação com clavulanato de potássio) & 1 \\
Azitromicina + Ceftriaxona & 1 \\
Cefalexina + Ciprofloxacino & 1 \\
Benzilpenicilina Benzatina + Norfloxacino + Benzilpenicilina Potássica (associação com procaína) & 1 \\
Azitromicina + Amoxicilina (associação com clavulanato de potássio) & 1 \\
\hline
\end{tabular}

TABELA III - Distribuição percentual de aquisições de medicamentos similares, genéricos e de referência, em sistema PBM, de janeiro a abril de 2005, na região de Campinas, SP

\begin{tabular}{|c|c|c|c|c|c|c|}
\hline \multirow[t]{2}{*}{ Fármaco } & \multicolumn{2}{|c|}{ Genérico } & \multicolumn{2}{|c|}{ Referência } & \multicolumn{2}{|c|}{ Similar } \\
\hline & $\mathrm{N}$ & $\%$ & $\mathrm{~N}$ & $\%$ & $\mathrm{~N}$ & $\%$ \\
\hline$\overline{\text { Amoxicilina }}$ & 150 & 51,4 & 39 & 13,4 & 103 & 35,3 \\
\hline Amoxicilina + Claritromicina + Associações & - & - & - & - & 5 & 100 \\
\hline Amoxicilina + Clavulanato Potássio & 10 & 21,3 & 24 & 51 & 13 & 27,7 \\
\hline Ampicilina & 6 & 75 & 2 & 25 & - & - \\
\hline Azitromicina & 41 & 22,2 & 27 & 14,6 & 117 & 63,2 \\
\hline Benzilpenicilina Benzatina & - & - & 14 & 100 & - & - \\
\hline Benzilpenicilina Potássica + Procaína & - & - & - & - & 2 & 100 \\
\hline Cefaclor & 13 & 32,5 & 27 & 67,5 & - & - \\
\hline Cefadroxila & 16 & 25,8 & 44 & 71 & 2 & 3,2 \\
\hline Cefalexina & 161 & 57,1 & 56 & 19,9 & 65 & 23 \\
\hline Cefazolina & - & - & 8 & 100 & - & - \\
\hline Ceftriaxona & 16 & 94,1 & - & - & 1 & 5,9 \\
\hline Cefuroxima & - & - & 5 & 100 & - & - \\
\hline Ciprofloxacino & 16 & 43,2 & 4 & 10,8 & 17 & 46 \\
\hline Claritromicina & 7 & 25,9 & 19 & 70,4 & 1 & 13,7 \\
\hline Doxiciclina & - & - & 3 & 100 & - & - \\
\hline Eritromicina & - & - & - & - & 6 & 100 \\
\hline Fenoximetilpenicilina Potássica & - & - & 3 & 100 & - & - \\
\hline Gatifloxacina & - & - & 7 & 77,8 & 2 & 22,2 \\
\hline Levofloxacino & - & - & 1 & 4,5 & 21 & 95,5 \\
\hline Limeciclina & - & - & 6 & 100 & - & - \\
\hline Lincomicina & - & - & 13 & 100 & - & - \\
\hline Norfloxacino & 22 & 41,5 & 16 & 30,2 & 15 & 28,3 \\
\hline Roxitromicina & - & - & 2 & 33,3 & 4 & 66,7 \\
\hline Sulfametoxazol + Trimetoprima & 6 & 17,1 & 25 & 71,4 & 4 & 11,4 \\
\hline Sultamicilina & - & - & 8 & 100 & - & - \\
\hline Tetraciclina & - & - & - & - & 8 & 100 \\
\hline Total & 464 & 38,5 & 353 & 29,4 & 386 & 32,1 \\
\hline
\end{tabular}

Nota: Foram excluídos desta tabela o cloranfenicol (monodroga e associação), a associação de neomicina com procaína, a nitrofurantoína e a telitromicina, por não existirem genéricos desses fármacos no mercado. 
TABELA IV - Distribuição percentual das vias e principais formas de apresentação dos antibióticos, em sistema PBM, de janeiro a abril de 2005, na região de Campinas, SP

\begin{tabular}{|c|c|c|c|c|c|c|c|c|}
\hline \multirow[t]{2}{*}{ Fármaco } & \multicolumn{2}{|c|}{ Via oral (sólido) } & \multicolumn{2}{|c|}{ Via oral (líquido) } & \multicolumn{2}{|c|}{ Injetável } & \multicolumn{2}{|c|}{ Outras vias } \\
\hline & $\mathrm{N}$ & $\%$ & $\mathrm{~N}$ & $\%$ & $\mathrm{~N}$ & $\%$ & $\mathrm{~N}$ & $\%$ \\
\hline Amoxicilina & 156 & 53,4 & 136 & 46,6 & - & - & - & - \\
\hline Cefalexina & 241 & 85,5 & 41 & 14,5 & - & - & - & - \\
\hline Azitromicina & 158 & 85,4 & 27 & 14,6 & - & - & - & - \\
\hline Cefadroxila & 51 & 83,2 & 11 & 17,7 & - & - & - & - \\
\hline Norfloxacino & 53 & 100 & - & - & - & - & - & - \\
\hline Amoxicilina + Clavulanato Potássio & 38 & 80,9 & 9 & 19,1 & - & - & - & - \\
\hline Cefaclor & 13 & 32,5 & 27 & 67,5 & - & - & - & - \\
\hline Ciprofloxacino & 36 & 97,3 & - & - & - & - & 1 & 2,7 \\
\hline Sulfametoxazol + Trimetoprima & 21 & 60 & 14 & 40 & - & - & - & - \\
\hline Claritromicina & 22 & 81,5 & 5 & 18,5 & - & - & - & - \\
\hline Levofloxacino & 22 & 100 & - & - & - & - & - & - \\
\hline Nitrofurantoína & 19 & 100 & - & - & - & - & - & - \\
\hline Ceftriaxona & - & - & - & - & 17 & 100 & - & - \\
\hline Benzilpenicilina Benzatina & - & - & - & - & 14 & 100 & - & - \\
\hline Lincomicina & 2 & 15,4 & - & - & 11 & 84,6 & - & - \\
\hline Cloranfenicol & 9 & 90 & - & - & - & - & 1 & 10 \\
\hline Gatifloxacina & 7 & 77,8 & - & - & - & - & 2 & 22,2 \\
\hline Ampicilina & 8 & 100 & - & - & - & - & - & - \\
\hline Cefazolina & - & - & - & - & 8 & 100 & - & - \\
\hline Sultamicilina & 6 & 75 & 2 & 25 & - & - & - & - \\
\hline Tetraciclina & 8 & 100 & - & - & - & - & - & - \\
\hline Eritromicina & 3 & 50 & 3 & 50 & - & - & - & - \\
\hline Limeciclina & 6 & 100 & - & - & - & - & - & - \\
\hline Roxitromicina & 6 & 100 & - & - & - & - & - & - \\
\hline Amoxicilina + Claritromicina + Associações & 5 & 100 & - & - & - & - & - & - \\
\hline Cefuroxima & 4 & 80 & 1 & 20 & - & - & - & - \\
\hline Doxiciclina & 3 & 100 & - & - & - & - & - & - \\
\hline Fenoximetilpenicilina Potássica & 3 & 100 & - & - & - & - & - & - \\
\hline Telitromicina & 4 & 100 & - & - & - & - & - & - \\
\hline Benzilpenicilina Potássica + Procaína & - & - & - & - & 2 & 100 & - & - \\
\hline Neomicina + Associações & - & - & - & - & - & - & 1 & 100 \\
\hline Total & 904 & 73,1 & 276 & 22,3 & 52 & 4,2 & 5 & 0,4 \\
\hline
\end{tabular}

\section{DISCUSSÃO}

Durante a caracterização do perfil de aquisição e prescrição dos antibióticos, foi observado que em um grupo homogêneo formado por indivíduos com acesso facilitado a atendimento médico e com incentivo para aquisição de medicamentos, o número médio de medicamentos por receita $(2,4)$ foi compatível com o relatado no Brasil por Santos e Nitrini (2004), Cunha et al. (2002), Lopes et al. (1996) e Simões e Mota (1997) — respectivamente 2,2; 2,$3 ; 2,2$ e $1,9-$, o que pode sugerir certo grau de polimedicação.
A maioria dos estudos que avaliam a utilização dos antimicrobianos aponta as infecções do trato respiratório como a principal causa de utilização desses medicamentos (Calvas, Bojalil, 1996), embora a etiologia viral seja a mais prevalente nessas doenças. Destaca-se que os dados analisados no presente estudo referem-se a um período de constância em temperaturas elevadas, quando supostamente a incidência de doenças respiratórias é mais baixa.

Foi observado que a amoxicilina, uma penicilina de amplo espectro, foi o fármaco mais prescrito (Tabela I). Dados semelhantes também foram obtidos por outros autores, tais como Calvas e Bojalil (1996), Marliére e Ferraz 
(2000), Thrane e Steffensen (1999) e Berquó et al. (2004), em pesquisas com o mesmo tema. A preocupação quanto à utilização desses grupos de antibióticos, que são fármacos de primeira escolha quando bem indicados, está no fato de que a amoxicilina, assim como a ampicilina, correspondem a um grupo de penicilinas cuja atividade antimicrobiana é ampliada de modo a incluir microorganismos Gram-negativos como Haemophilus influenzae, E. coli e Proteus mirabilis. Infelizmente, um dos principais mecanismos de resistência bacteriana está no fato de que esses fármacos são facilmente hidrolisados pelas $\beta$-lactamases de amplo espectro encontradas com freqüência cada vez maior em isolados clínicos dessas bactérias Gram-negativas (Moland et al., 2002). O mesmo se pode dizer sobre a associação de amoxicilina com clavulanato, que aparece neste estudo entre os medicamentos mais vendidos.

Uma limitação importante do presente trabalho está na impossibilidade da obtenção de dados acerca do diagnóstico que levou à utilização dos antibióticos. Entretanto, mostra-se preocupante a excessiva prescrição de macrolídeos. Destaca-se que 17,3\% das prescrições obtidas durante os meses analisados foram de azitromicina. A Sociedade Brasileira de Pediatria (SBP), em seu II Consenso sobre Prevenção da Febre Reumática (II CONSENSO, [s.d.]), advertiu que o uso de novos macrolídeos, a exemplo da azitromicina, como fármacos de primeira linha para o tratamento da faringoamigdalite estreptocócica, não é recomendado, pois pode levar a um rápido aumento da resistência bacteriana, ampliando as dificuldades para o tratamento de pacientes alérgicos à penicilina.

Entre as cefalosporinas, destacaram-se a cefalexina e outras de primeira geração. No entanto, observou-se a prescrição de ceftriaxona (cefalosporina de terceira geração) que geralmente tem indicação apenas no ambiente hospitalar. De forma similar, as quinolonas que possuem aplicação como reserva terapêutica para infecções tratadas no hospital foram amplamente prescritas para infecções comunitárias.

Outro dado que chama a atenção é a clara preferência pela utilização de medicamentos genéricos ou similares entre os três antibióticos mais adquiridos. Entretanto, com relação à escolha de medicamentos pertencentes à lista de desconto oferecida pela empresa de PBM, observa-se que a aquisição desses produtos é extremamente baixa, especialmente considerando-se que essa oferta de desconto atinge $58 \%$ dos produtos adquiridos, com abatimentos de até $36 \%$ no preço de fábrica.

Uma importante observação foi que o percentual de aquisição de medicamentos de referência é de $29,4 \%$ em relação ao total, valor destoante dos percentuais encontrados para os três antibióticos mais vendidos e, possivelmente, mais lucrativos (amoxicilina, 13,4\%; azitromicina, 14,6\%; cefalexina, 20,1\%). Uma possível inferência é que o usuário, em primeira análise, não é sensível ao preço dos medicamentos adquiridos, já que a empresa contratante oferece $70 \%$ de subsídio em todos os medicamentos prescritos. Entretanto, provavelmente os usuários são suscetíveis às interferências ocorridas nos estabelecimentos durante a aquisição do medicamento prescrito, em detrimento da política de desconto promovida pela empresa de PBM.

É relevante esclarecer que, embora o sistema PBM permita identificar exatamente o que foi adquirido pelo usuário nos estabelecimentos credenciados, não garante que a apresentação dispensada venha a ser fiel à indicação do prescritor, nem que haverá cumprimento integral do receituário.

Ainda que não fizesse parte do objetivo desta pesquisa o monitoramento dos usuários com infecções reincidentes, pôde-se constatar que alguns usuários (1) fizeram aquisições consecutivas de um mesmo antibiótico ao longo dos meses (sempre com receitas diferentes), (2) adquiriram dois ou mais antibióticos diferentes em compras separadas, sendo que os dados sobre prescrições comprovaram a busca por atendimento médico mais de uma vez no período, ou (3) adquiriram antibióticos diferentes com uma única prescrição médica, gerando na maioria dos casos dispensações incoerentes. Tais constatações ampliam a compreensão de que o controle do surgimento de bactérias resistentes não pode se limitar à prescrição médica embasada por guias ou protocolos, mas também deve ser fruto de um atendimento médico de qualidade e da dispensação responsável. A interação entre paciente, médico e farmacêutico constitui portanto elemento fundamental para o bom resultado da terapêutica.

A participação de um profissional farmacêutico que atue não apenas no aspecto gerencial, e sim no contato direto com os usuários, seja na dispensação, no acompanhamento da utilização dos medicamentos, na orientação ao uso e nas ações coletivas, contribuiria efetivamente para a otimização dos recursos fornecidos pelo Sistema de Saúde. O incentivo ao uso racional dos medicamentos, que inclui o fornecimento de orientações para que seu consumo seja adequado, a educação dos pacientes para a adesão aos tratamentos e a dos profissionais para uma prescrição racional e correta são algumas das atividades que estão sob responsabilidade da profissão farmacêutica, mesmo que tal responsabilidade não lhe seja exclusiva (Borges, Nascimento Jr., 2005).

\section{CONCLUSÃO}

Pode-se concluir que o sistema PBM permite extrair informações relevantes sobre antibióticos de efeitos sistêmicos, através da caracterização da prescrição e do 
perfil de aquisição desses fármacos quanto ao tipo, à quantidade de unidades de venda adquiridas, aos laboratórios envolvidos e aos valores financeiros relacionados às aquisições, garantindo maior precisão dos resultados em todas as análises aqui propostas.

Uma potencialidade do sistema PBM para a empresa contratante, confirmada pela análise dos dados, é a facilidade na aquisição de medicamentos após a consulta médica, bem como a possibilidade de monitoramento adequado, pelo médico do trabalho, dos usuários que apresentem infecções reincidentes.

A sugestão deste estudo para aprimorar o perfil de aquisição consiste em acrescentar ao sistema ferramentas que lhe permitam cruzar dados sobre gênero, faixa etária e grau de escolaridade dos usuários.

\section{ABSTRACT \\ Use of Pharmacy Banafits Management (PBM) system to describe the profile of antibiotic prescription and purchase}

Pharmacy Benefits Management (PBM), a system that manages benefits in the purchase and sale of drugs, is of relatively recent implementation in Brazil. Taking into account that the development of bacterial resistance is related to the inadequate prescription of antibiotics or to the use of low activity antibiotics, this study sought to assess the capability of PBM to provide useful information on the profiles of prescription and purchase of systemic antibiotics. The data used for this purpose were collected from the database of a Brazilian PBM company and related to a group of 6525 metalworkers of a company located in the region of Campinas, SP, and to their dependents, covering the period from January to April 2005. Of the drugs purchased, $7.7 \%$ were systemic antibiotics, with a mean of 2.4 antibiotics and a mean cost of $R \$ 51.80$ per prescription. Amoxicillin was the most prescribed drug. In $92.7 \%$ of cases, users purchased the prescribed drug within one day of the medical visit. Based on the lists of purchased pharmaceutical specialties (per retail package), manufacturers, antibiotics present in the composition of each product, prescription dates, and dispensation dates, the system was found capable of providing relevant information on the theme investigated.

UNITERMS: Pharmacy Benefits Management. Antibiotics/ prescription. Drugs/prescription. Drugs/purchase.

\section{REFERÊNCIAS BIBLIOGRÁFICAS}

BERQUÓ, L.S.; BARROS, A.J.D.; LIMA R.C.; BERTOLDI, A.D. Utilização de medicamentos para tratamento de infecções respiratórias na comunidade. Rev. Saúde Pública, v.38, n.3, p.359-364, 2004.

BORGES, F.P.; NASCIMENTO JÚNIOR., J.M. Assistência farmacêutica na atenção primária à saúde - APS. In: CORDEIRO, B.C.; LEITE, S.N. (Orgs.). O farmacêutico na atenção à saúde. Itajaí: Universidade do Vale do Itajaí, 2005. 189 p.

BRASIL. Ministério da Saúde. Secretaria de Ciência, Tecnologia e Insumos Estratégicos. Departamento de Assistência Farmacêutica e Insumos Estratégicos. Relação Nacional de Medicamentos Essenciais: RENAME. Brasília: Ministério da Saúde, 2006. 286 p.

CALVAS, J.; BOJALIL, R. Antibiotic use in a periurban community in México: a household and drugstore survey. Soc. Sci. Med., v.42, p.1121-1128, 1996.

CUNHA, M.C.N.; ZORZATTO, J.R.; CASTRO, L.L.C. Avaliação do uso de medicamentos na rede pública municipal de saúde de Campo Grande, MS. Rev. Bras. Ciênc. Farmac., v.38, p.217-227, 2002.

II CONSENSO sobre Prevenção da Febre Reumática (Sociedade Brasileira de Pediatria). [s.d.]. Disponível em: $<$ http://www.sbp.com.br/show_item2.cfm?id_categoria $=24 \&$ id detalhe $=1613 \&$ tipo_detalhe $=\mathrm{s}>$. Acesso em: 10 jul. $200 \overline{6}$.

JACOBS, M.R.; WEINBERG, W. Evidence-based guidelines for treatment of bacterial respiratory tract infections in the era of antibiotic resistance. Manag. Care Interface, v.4, n.14, p.68-80, 2001.

LOPES, A.E.C.; TEIXEIRA, A.C.A.; GURGEL, M.L.F.; MIRANDA, M.C.C. Drug use of evaluation in health services in Fortaleza, Brasil. INRUD News, v.6, p.17, 1996.

MARLIÉRE, G.; FERRAZ, M. Consumo ambulatorial e sobras de antibióticos: entrevista em 6000 domicílios brasileiros. Rev. Bras. Med., v.57, p.187-195, 2000. 
MOLAND, E.S.; BLACK, J.A.; OURADA, J.; REISBIG, M.D.; HANSON, N.D.; THOMSON, K.S. Occurrence of newer beta-lactamases in Klebsiella pneumoniae isolates from 24 U.S. hospitals. Antimicrob. Agents Chemother., Washington, v.46, n.12, p.3837-3842, 2002.

MORTIMER, R.O. Demand for prescription drugs: the effects of managed care pharmacy benefits. Berkeley, CA: University of California, 1997. 56 p. Disponível em: $<$ http://129.3.20.41/econ-wp/hew/papers/9802/ 9802002.pdf>. Acesso em: 31 jul. 2006.

SANTOS, V.; NITRINI, S.M.O. Indicadores do uso de medicamentos prescritos e de assistência ao paciente de serviços de saúde. Rev. Saúde Pública, v.38, n.6, p.819834, 2004.

SIMÕES, M.J.S.; MOTA, M.A. Indicadores do uso de medicamentos em unidade municipal de saúde de Ribeirão Preto, SP. Rev. Infarma, v.6, p.12-16, 1997.
SMITH, R.D.; COAST, J. Antimicrobial resistance: a global response. Bull. World Health Organ., v.80, n.2, p.126133, 2002.

THOMAS, N.; LARSON, L.; BELL, N. Pharmacy Benefits Management. Brookfield, Wis.: International Foundation of Employee Benefit Plans, 1996. 144p.

THRANE, N.; STEFFENSEN, F. A population-based study of antibiotic prescriptions for Danish children. Pediatr. Infect. Dis. J., v.18, p.333-337, 1999.

P.R. VADE MÉCUM 2004/2005. 10. ed. Rio de Janeiro: Soriak, 2004. 1264p.

Recebido para publicação em 25 de julho de 2006 Aceito para publicação em 13 de novembro de 2007 